\title{
Comparison of different magnet arrangement on performance of flux reversal permanent magnet (FRPM) machine
}

\author{
M. H Remlan, R. Aziz, S. Salimin
}

Departement of Electrical and Electronic Engineering, University Tun Hussein Onn Malaysia, Malaysia

\begin{tabular}{l}
\hline \hline Article Info \\
\hline Article history: \\
Received Sep 9, 2018 \\
Revised Jan 16, 2019 \\
Accepted Mar 27, 2019 \\
\hline
\end{tabular}

Keywords:

Finite element analysis Flux reversal Magnet arrangement Permanent magnet Polarities

\begin{abstract}
This paper offers the analysis of performance of Flux Reversal Permanent Magnet (FRPM) machines with different type of magnet arrangements. There are two designs that have been proposed in this report, which one of them has a pair of permanent magnets (PM) with alternate polarities place on surface of stator tooth and the polarities of two adjacent PM at these two stators are identical. This PM arrangement is called as NS-SN configuration. Second design is NS-NS configuration that has different PM polarities on different stator tooth. By comparing this PM arrangement, generally the NSNS configuration offers high speed and power. However, the NS-SN configuration shows higher maximum torque compared to the previous design. The design process for both configu rations is completely using finite element analysis (FEA) which is JMAG-Designer. To make sure the coil phase is in correct position, the design configuration with coil arrangement tests are evaluated. Finally, each flux of both designs been observed by analyse their torque with various armature current density.
\end{abstract}

Copyright (C) 2019 Institute of Advanced Engineering and Science. All rights reserved.

\section{Corresponding Author:}

Roziah Aziz,

Departement of Electrical and Electronic Engineering,

University Tun Hussein Onn Malaysia (UTHM),

86400 Parit Raja, Johor, Malaysia.

Email:roziah@uthm.edu.my

\section{INTRODUCTION}

Permanent magnet (PM) motors basically consist of two parts which are stator and rotor. The stator is a stationary part in the motor and it is powered by alternating current then produces an electric field. While the rotor itself is a moving part in an electric motor and the interaction between winding in the stator and magnetic fields will make is rotate and produce torque around rotor's axis [1]. Permanent magnet usually located at rotor which is called rotor-PM but there are new designs of PM that can be located at stator which know as stator-PM [2-5]. There are three types of stator-PM machines which are doubly salient PM (DSPM), flux-switching PM (FSPM) machines, and lastly is flux-reversal PM (FRPM) machine [6-12]. Flux reversal permanent magnet (FRPM) machine was first introduced in 1997 for the purpose of combining the advantages of switched reluctance machine (SRM) with the robust rotor structure and permanent magnet machine with large torque density [13]. This combinations produce high performances of machine especially in their simple construction, high fault tolerance, easy maintenance and fast transient response [14]. This makes FRPM machine had been used around the world in many applications such as in electric vehicle, lowspeed servo systems and direct-drive winding power generation [15-16]. Figure 1 shows that the conventional three-phase FRPM machine which is the PMs are mounted on the inner part of the stator teeth and the concentrated windings. 


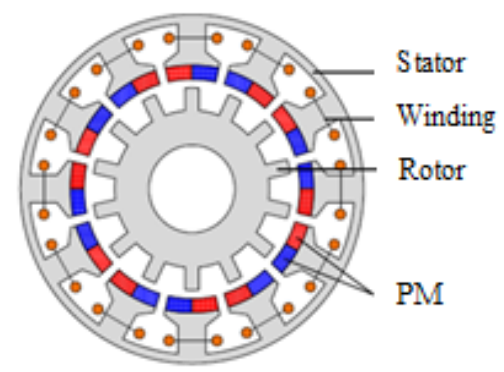

Figure 1. Cross section of a conventional FRPM machine

The first doubly salient stator permanent magnet machine (DSPMM) was introduced in 1955, called flux switch alternator. This machine was made by combining SRM and brushless DC motor (BLDCM) due to high cost of rare earth permanent magnet. However, the rotor volume was poor, stator vibration and difficulty in stator manufacturing. In order to overcome the problem of torque density, stator vibration, and simplify the process of manufacturing, the first single phase flux reversal machine (FRM) was introduced in 1997. To maintain the advantages of single phase FRM at the same time to reduce the cogging torque, the three phase FRM was introduced in 1999 [17].

Nowadays, several efforts have been made in order to analyse and improve the performance of FRPM machines. The performance of FRPM machine may be improved if the permanent magnet arrangement is rearranged. The arrangement can be made by comparing the magnet arrangement based on their polarities. In this research, a comprehensive analysis of performance different in FRPM machines with various magnet arrangements in provided. There are two arrangements of PM that will be analysed. First one as shown in Figure 2(a) is a pair of PM pieces of alternate polarities is mounted on the inner surface of each stator tooth, and the polarities of two adjacent magnets belonging to two stators are identical. The other one is as shown in Figure 2(b) which is the polarities of the two adjacent magnets is in opposite polarities.

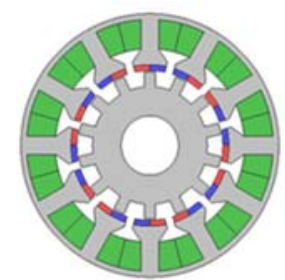

(a)

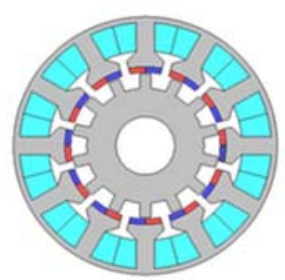

(b)

Figure 2. Different PM arrangement

\section{RESEARCH METHOD}

The geometry editor is used in this project to design each part of the machine such as stator, rotor, permanent magnet (PM), and armature coil separately. To design the machine, the following parameters in Table 1 must be followed.

Table 1. Design parameters of 12S-14P FRPMM

\begin{tabular}{cccc}
\hline Parameter & Value & Parameter & Value \\
\hline Stator pole/slot numbers & 12 & Shaft radius & $10 \mathrm{~mm}$ \\
Rotor pole numbers & 14 & Inner radius of stator & $27.5 \mathrm{~mm}$ \\
Outer radius of stator & $45 \mathrm{~mm}$ & Permanent magnet width & $2 \mathrm{~mm}$ \\
Air gap length & $0.5 \mathrm{~mm}$ & Number of turns per phase & 42 \\
Rotor pole length & $5 \mathrm{~mm}$ & Rated speed & $600 \mathrm{r} / \mathrm{min}$ \\
Outer radius of rotor & $25 \mathrm{~mm}$ & & \\
\hline
\end{tabular}

Int J Pow Elec \& Dri Syst, Vol. 10, No. 3, Sep 2019 : 1207 - 1214 
Table 2 shows the material and condition setting for FRPM machine parts. The rotation of motor is set to $600 \mathrm{r} / \mathrm{min}$ and the arrangement of FEM coils of each armature coil also been set.

Table 2. Materials and condition setting for FRPM machines

\begin{tabular}{ccc}
\hline Parts & Materials & Conditions \\
\hline Rotor & Nippon Steel 35H210 & Motion: rotation \\
Torque: nodal force \\
$\begin{array}{c}\text { Armature Coil } \\
\text { Permanent Magnet }\end{array}$ & $\begin{array}{c}\text { Nippon Steel 35H210 } \\
\text { Conductor Copper } \\
\text { Neomax-35AH (irreversible) } \\
\text { (Magnetization pattern: radial direction) }\end{array}$ & - \\
\hline
\end{tabular}

\section{RESULTS AND ANALYSIS}

The design configuration like rotor, stator, permanent magnets and armature winding had been completed by using Geometry Editor.

\subsection{No-load analysis}

Figure 3 shows the UVW fluxes for NS-SN configuration FRPM machine and Figure 4 shows the UVW fluxes for NS-NS configuration FRPM machine.

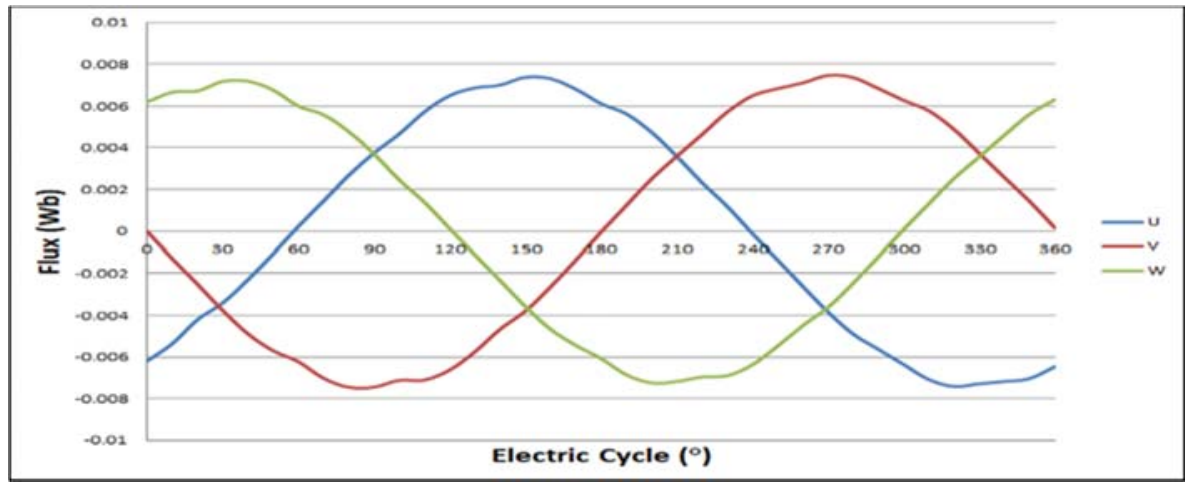

Figure 3. UVW fluxes for NS-SN configuration FRPM machine

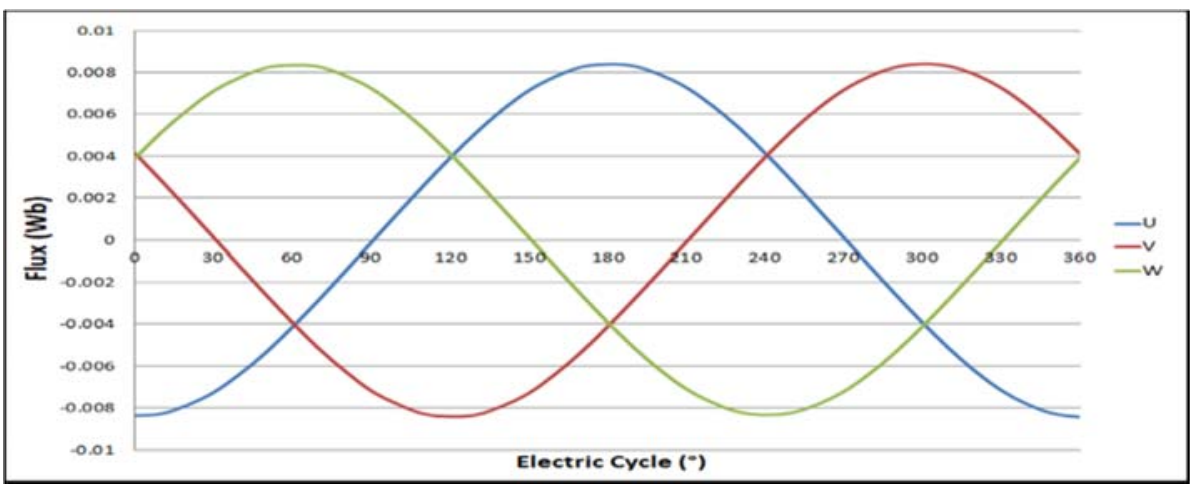

Figure 4. UVW fluxes for NS-NS configuration FRPM machine

The usage of zero rotor position is to verify the maximum flux as lead to the highest torque that can be achieved. To achieve the zero-rotor position, maximum of $U$ flux was $180^{\circ}$ and their intercept at $90^{\circ}$ and $270^{\circ}$ at the graph. The rotor was adjusted by estimating the degree of change when $U$ flux is not in zero rotor position. Figure 5 for both NS-SN and NS-NS configuration shows the accurate zero rotor position in the U flux graph.

Comparison of different magnet arrangement on performance of flux reversal permanent ... (M. H Remlan) 


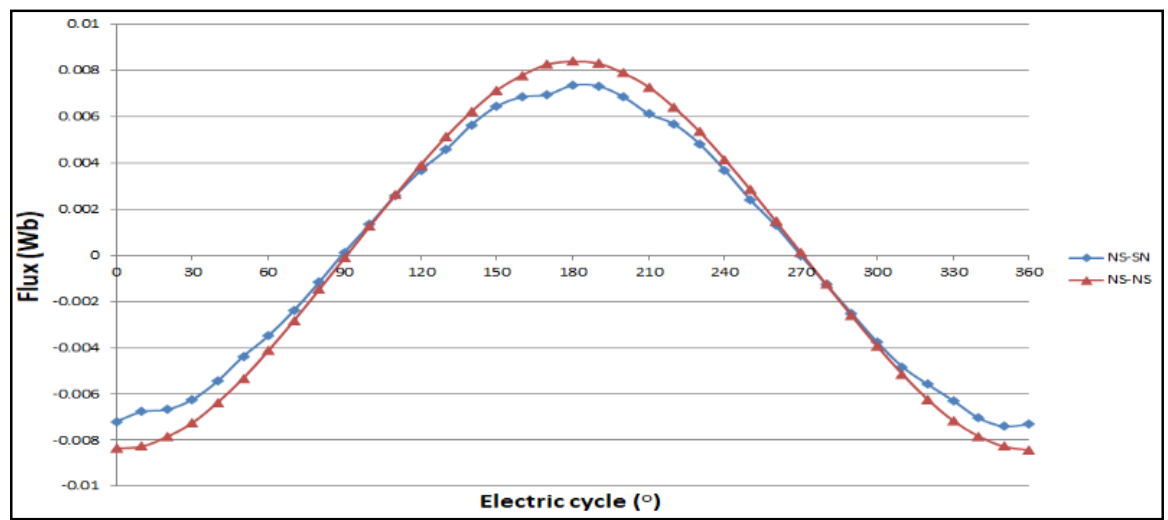

Figure 5. U flux in zero rotor position for NS-SN and NS-NS configuration

Figure 6 shows the flux line and the flow of force field through permanent magnet. Figure 6(a) shows the flux line stray and this will cause back EMF and lead to bad effect to the design.

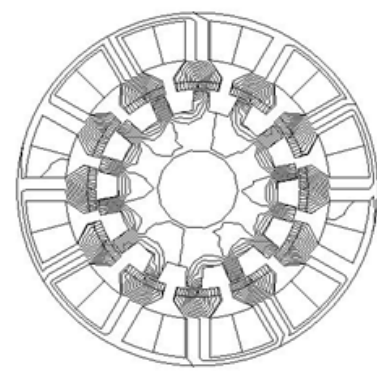

(a)

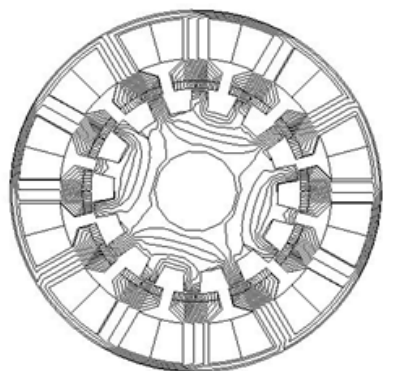

(b)

Figure 6. Flux line (a) NS-SN (b) NS-NS configuration

Figure 7 shows the cogging torque for both FRPM machine. Cogging torque happened due to interaction between rotor and stator with permanent magnet. Through the analysis, figure below shows that NS-SN configuration has higher peak cogging torque which is $0.1423 \mathrm{Nm}$ than NS-NS configuration which is $0.1132 \mathrm{Nm}$. Besides that, NS-SN has low torque ripple compared to NS-SN FRPM machine.

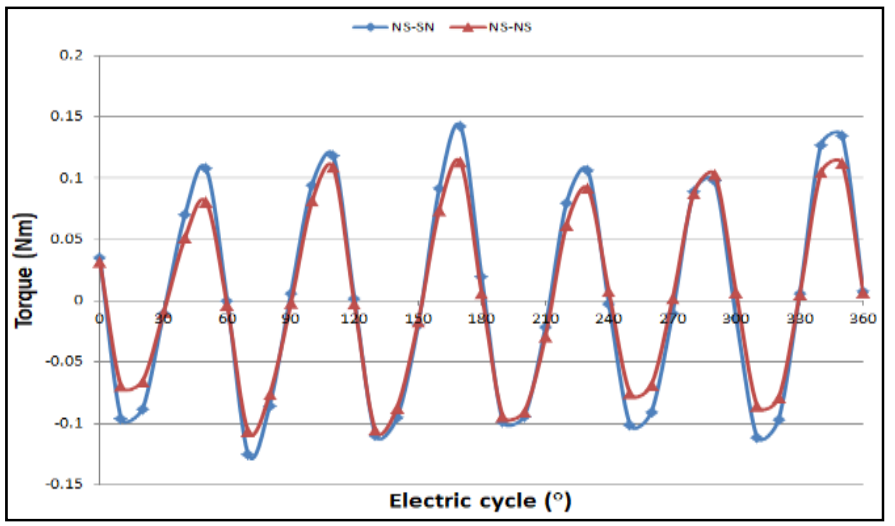

Figure 7. Cogging for NS-SN and NS-NS configuration 


\subsection{Load analysis}

Figure 8 shows the graph torque versus various armature densities, $\mathrm{J}_{\mathrm{A}}$. The graph was plotted in $\mathrm{J}_{\mathrm{A}}$ start from $0 \mathrm{~A} / \mathrm{mm}^{2}-30 \mathrm{~A} / \mathrm{mm}^{2}$ by increasing $5 \mathrm{~A} / \mathrm{mm} 2$ for each step. Then, injected current were calculated by using equation below. Armature coil slot area is same for both designs which are $69.451957 \mathrm{~A} / \mathrm{mm}^{2}$.

$$
I_{A}=\frac{\sqrt{2} a_{A} J_{A} S_{A}}{N_{A}}
$$

Where,

$\mathrm{I}_{\mathrm{A}}=$ Injected current

$\mathrm{J}_{\mathrm{A}}=$ Armature coil current density (set to maximum of $30 \mathrm{~A} / \mathrm{mm} 2$ )

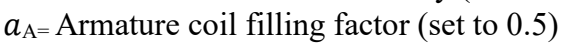

$\mathrm{S}_{\mathrm{A}}=$ Armature coil slot area

$\mathrm{N}_{\mathrm{A}}=$ Number of turn of armature coil

Table 4. Value of $\mathrm{I}_{\mathrm{A}}$ when $\mathrm{J}_{\mathrm{A}}$ in NS-SN and NS-NS configuration

\begin{tabular}{cc}
\hline $\mathrm{J}_{\mathrm{A}}\left(\mathrm{A} / \mathrm{mm}^{2}\right)$ & $\mathrm{I}_{\mathrm{A}}(\mathrm{A})$ \\
\hline 30 & 35.079 \\
25 & 29.232 \\
20 & 23.338 \\
15 & 17.54 \\
10 & 11.693 \\
5 & 5.846 \\
0 & 0
\end{tabular}

From the torque versus current density analysis, the maximum torque can be observed from different armature coil current density. Figure 8 shows that the highest torque that can be achieve is 2.682 $\mathrm{Nm}$ at $30 \mathrm{~A} / \mathrm{mm}^{2}$ for NS-SN configuration and $2.642 \mathrm{Nm}$ at $30 \mathrm{~A} / \mathrm{mm}^{2}$ for NS-NS configuration.

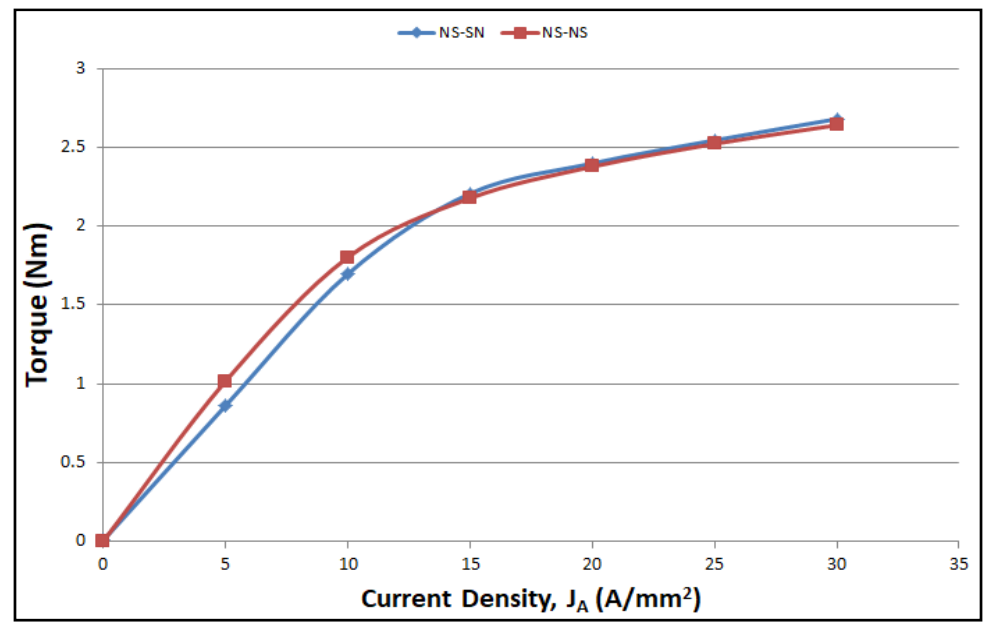

Figure 8. Torque versus various armature current density

Torque versus speed graph is use to analysed the maximum torque and maximum speed of the motor. Figure 9 shows that when speed is $41398.6 \mathrm{rpm}$, the torque is $0.2887 \mathrm{Nm}$. Meanwhile, in Figure 10 shows at speed is $17923.3 \mathrm{rpm}$, the torque is low which is about $0.1630 \mathrm{Nm}$. From this analysis shows that NS-SN configuration has high in torque and speed compared to NS-NS configuration.

For the power versus speed in Figure 9 shows that the highest speed that generate for NS-SN configuration is $1818.5 \mathrm{~W}$, while in Figure 10 shows NS-NS configuration has low speed than previous configuration which is only $319.77 \mathrm{~W}$. The power can be calculated by using the equation below.

Comparison of different magnet arrangement on performance of flux reversal permanent ... (M. H Remlan) 


$$
P=\frac{2 \pi}{60} \times T \times S
$$

Where,

$\mathrm{P}=$ power generate

$\mathrm{S}=$ speed of motor

$\mathrm{T}=$ torque

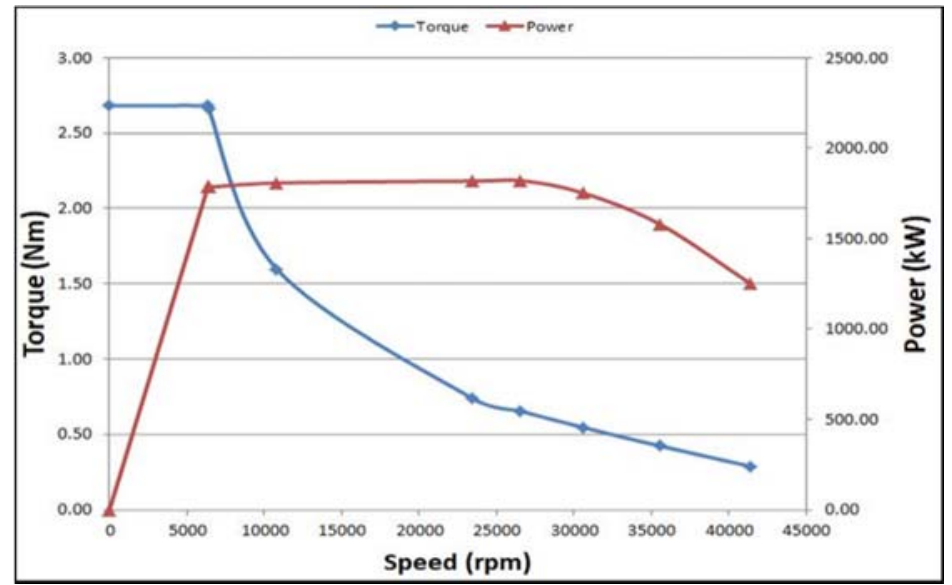

Figure 9. Torque and power versus speed graph for NS-SN configuration

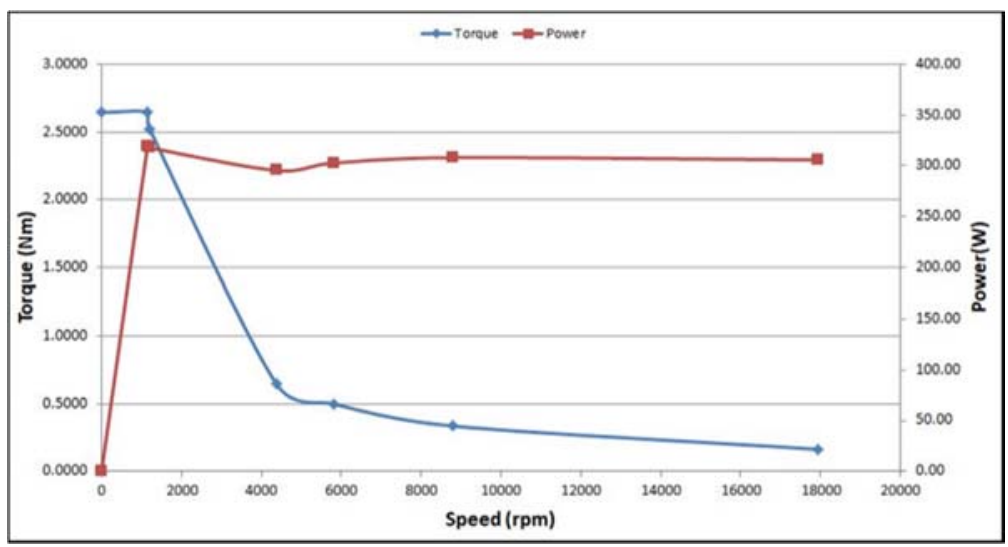

Figure 10. Torque and power versus speed graph for NS-NS configuration

\section{CONCLUSION}

In this project, the study of 12Slot-14Pole FRPM machines of NS-SN and NS-NS configuration had been investigated. The procedures to design FRPM machine had been discussed clearly explained. The coil arrangement test for the design had been examined to validate each of the armature coil phase and to proof the operating principle of machines. Besides that, the performances of both design FRPM machines such as flux line, final torque and power have been investigated. From the investigation, both design had its own performances. There are significant difference in performance between NS-SN and NS-NS configuration of FRPM machine, where NS-SN configuration produces high torque and speed as compared to NS-NS configuration. This shows that NS-SN configuration better than NS-NS configuration. Finally, the proposed designs are suitable for various applications that need various performances. 


\section{ACKNOWLEDGEMENTS}

The authors gratefully acknowledge the contribution of Research Management Center (RMC), Universiti Tun Hussein Onn Malaysia (UTHM), Batu Pahat, Johor, Malaysia for the financial support of this research. This research is partly by RMC under the U850 (Tier 1) Grant.

\section{REFERENCES}

[1] R. S. Khhurmi and J. K. Gupta, Theory of Machines. Eurasia Publishing House (pvt).Ltd., 2010.

[2] W.H.Tai, M.C Tsai, Z.L Gaing, P.W Huang, and Y.S Hsu, "Novel Stator Design of Double Salient Permanent Magnet Motor," IEEE Transactions on Magnetics, vol. 50, No. 4, April 2014.

[3] H. Mingjie and X. Wei, "Novel Single Phase Doubly Salient Permanent Magnet Machine with Asymmetric Stator Poles," IEEE, 2016.

[4] L. Yi and M. Zhao, "Doubly Salient Permanent Magnet Motor Development Review," Third International Conference on Instrumentation, Measurement, Computer, Communication and Control, 2013.

[5] M. Cheng and K.T Chau, "Static Characteristics of A New Doubly Salient Permanent Magnet Motor," IEEE Transactions on Energy Conversion, Vol. 16, No. 1, March 2001.

[6] X.Liu, D.Wu, Z.Q. Zhu, A.Pride, R.P Deodhar, and T. Sasaki, "Efficiency Improvement of Switched Flux PM Memory Machine Over Interior PM Machine for EV/HEV Applications," IEEE Transactions on magnetics, Vol. 50, No. 11, Nov 2014.

[7] S. Zhu, M. Cheng, W. Hua, X. Cai and M. Tong, "Finite Element Analysis of Flux-Switching PM Machine Considering Oversaturation and Irreversible Demagnetization," IEEE Transactions on Magnetics, Vol. 51, No. 11, Nov 2015.

[8] Y. Pang, Z. Q. Zhu, D. Howe, S. Iwasaki, R. Deodhar, and A. Pride, "Comparative Study of Flux-Switching and Interior Permanent Magnet Machines," Proceeding of International Conference on Electrical Machines and Systems, 2007.

[9] A. Thomas, Z.Q. Zhu, G.W. Jewell, and D. Howe, "Flux-Switching PM Brushless Machines with Alternative Stator and Rotor Pole Combinations," International Conference on Electrical Machines and Systems, 2008.

[10] H. Y. Li and Z. Q. Zhu, "Analysis of Flux-Reversal Permanent-Magnet Machines With Different Consequent-Pole PM Topologies," IEEE Transactions on Magnetics, Vol. 54, No. 11, Nov 2018.

[11] Z.Han, L. Guangyou, S. Yuping and X.Yanliang, "Comparative analysis of the methods to reduce flux linkage in Flux Reversal Machine," International Conference on Electrical Machine and Systems, 2010.

[12] X. Zhu and W.Hua, "An Improved Configuration for Cogging Torque Reduction in Flux-Reversal Permanent Magnet Machines," IEEE Transcations on Magnetics, Vol.53, No. 6, June 2017.

[13] R. P. Deodhar, S. Andersson, I. Boldea, and T. J. E. Miller, "The flux-reversal machine: A new brushless doublysalient permanent-magnet machine," IEEE Trans. Ind. Appl., vol. 33, no. 4, pp. 925-934, 1997.

[14] C. Wang, S. a. Nasar, and I. Boldea, "Three-phase flux reversal machine (FRM)," IEE Proc. - Electr. Power Appl., vol. 146, p. 139, 1999.

[15] X. Zhu, W. Hua, M.Cheng and G.Zhang, "An Improved Configuration for Cogging Torque Reduction in FluxReversal Permanent Magnet Machines," IEEE Conference on Electromagnetic Field Computation (CEFC), 2016.

[16] M. Cheng and Y.Shu, "Flux Weakening Control for Stator-Doubly-Fed Doubly Salient Motor," World Electric Vehicle Journal ,Vol. 4, ISSN 2032-6653, 2010.

[17] Y. Gao, D.Li,R.Qu, and J.Li, “Design Procedure of Flux Reversal Permanent Magnet Machines,” IEEE Trans. Ind. Appl., vol. 53, no.5, pp 4232-4241, 2017. 


\section{BIOGRAPHIES OF AUTHORS}

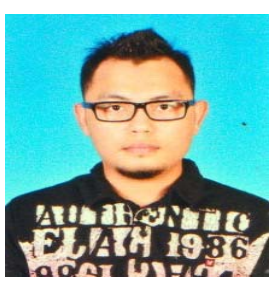

Muhamad Hazwan received the degree in electrical engineering, University Tun Hussein Onn Malaysia in 2019.

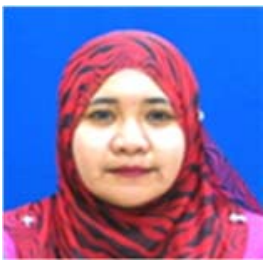

Roziah Aziz is a lecturer in Faculty of Electrical Engineering (FKEE), UTHM. After graduated from her first degree in Eletrical Engineering (UTM-2005), she worked as a tutor in UTHM and pursue her study in Master Engineering in Power Electrical Engineering in UTHM. She is now pursuing her PhD in Electrical Engineering at Newcastle University, UK. Her research interests are in electrical machine design and permanent magnet machines

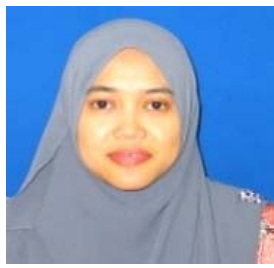

Suriana Salimin is a lecturer in Faculty of Electrical Engineering (FKEE), UTHM. After graduated from her first degree in Eletrical Engineering (UTM-2006), she worked as a tutor in UTHM for 6 months and continued for MSc in Power Distribution Engineering in Newcastle University (2007). She completed her $\mathrm{PhD}$ in Electrical Engineering in 2014 also from Newcastle University, UK. She has published a few papers in Jurnals and proceeding since 2013. Her research interests are on power quality improvement, distributed generation systems, renewable energy and harmonics mitigation. 